\title{
Enfermagem: a prática do cuidado sob o ponto de vista filosófico'
}

\author{
Vera Regina Waldow²
}

doi:10.11144/Javeriana.IE17-1.epdc

Como citar: Waldow VR. Enfermagem: a prática do cuidado sob o ponto de vista filosófico. Investig Enferm. Imagen Desarr. 2015;17(1):13-25. http://dx.doi.org/10.11144/Javeriana. IE17-1.epdc

1. Artigo de reflexão. Recebido: 18 de março de 2014. Revisado: 7 de abril ao 22 de maio de 2014. Aceito: 23 de julho de 2014.

2. Enfermeira. Professora aposentada pela Escola de Enfermagem da Universidade Federal do Rio Grande do Sul. Dra. (EdD-USA) em Educação em Enfermagem. Correio eletrônico: waldowvr@portoweb.com.br. 


\section{Resumo}

Embora o cuidado não seja uma temática nova, sua discussão é pertinente, pois vários aspectos ainda permanecem vagos. Este texto tem como objetivo primordial expor algumas das ideias da autora do presente manuscrito sobre o cuidado em geral e como o visualiza no contexto da enfermagem. Utiliza uma exposição teórica sobre o cuidar/cuidado e sua interpretação de ordem filosófica, com bases na fenomenologia e no holismo, visa contribuir para uma melhor compreensão deste fenômeno e para uma prática de enfermagem mais humanista. A análise filosófica propicia um olhar sob o qual a autora entende o cuidar como um elemento da linguagem da enfermagem; é uma forma de ser e só ocorre na presença de outros seres. Conclui que o cuidado, apoiada em outros autores, constitui a essência da enfermagem e se caracteriza por suas dimensões existenciais, relacionais e contextuais.

Palavras chave: enfermagem; cuidado de enfermagem; cuidadores; pacientes; fenomenologia; holismo

\section{Enfermeria: la práctica del cuidado desde un punto de vista filosófico}

\section{Resumen}

Aunque el cuidado no sea una temática nueva, su discusión sigue siendo pertinente, pues varios aspectos todavía permanecen vagos. Este texto tiene como objetivo primordial exponer algunas de las ideas de la autora del presente manuscrito sobre el cuidado en general y cómo lo visualiza en el contexto de la enfermería. Se hace una exposición teórica sobre el cuidar/cuidado y su interpretación de orden filosófico con base en la fenomenología y en el holismo, en busca de contribuir a una mejor comprensión de este fenómeno y a una práctica de la enfermería más humanista. El análisis filosófico propicia una mirada bajo la cual la autora entiende el cuidar como un elemento del lenguaje de la enfermería; es una forma de ser y solo sucede en presencia de otros seres. Apoyada en otros autores, concluye que el cuidado constituye la esencia de la enfermeria y se caracteriza por sus dimensiones existenciales, relacionales y contextuales.

Palabras clave: enfermería; cuidado de enfermería; cuidadores; pacientes; fenomenologia; holismo 


\section{Nursing: the Care Practice from a Philosophical Point of View}

\section{Abstract}

Although care is not a new topic, the discussion about it remains relevant, as several aspects are still vague. This text aims primarily to expose some of the ideas of the author of this manuscript about care in general and how to visualize it in the context of nursing. It is presented a theoretical discussion of caring / care and its philosofical interpretation based on phenomenology and holism, seeking to contribute to a better understanding of this phenomenon and to a more humanistic practice of nursing. The philosophical analysis favors a conception under which the author understands caring as an element of the language of nursing; it is a way of being and only happens in the presence of other beings. Supported by other authors, she concluded that caring is the essence of nursing and is characterized by its existential, relational and contextual dimensions.

Keywords: nursing; nursing care; caregivers; patients; phenomenology; holism 


\section{Introdução}

O presente trabalho se orienta através de uma perspectiva filosófica, tomando por empréstimo algumas considerações de autores da filosofia e inspirando-se, em vários momentos, pela antropologia filosófica. Ao privilegiar a categoria cuidado como tema de interpretação, se utilizaram as ideias de Martin Heidegger, que faz uma análise de cunho fenomenológico existencial sobre o ser e o cuidar como sua essência.

A filosofia refere-se à totalidade do ser, questionando esse ser e sobre sua essência. Contudo, o filosofar significa estar-a-caminho, ou seja, está numa constante busca, a qual é permeada por questionamentos que, em geral, não levam a conclusão alguma; o seu modo de certeza não é científico (1).

A antropologia filosófica (2) oferece uma visão integral, global e holística do ser humano em sua circunstância. Ao propor uma reflexão integral sobre a condição humana, a antropologia filosófica inclui a ética e constitui uma de suas dimensões. O ser humano é um ser moral que emite juízos de valor sobre a realidade, julga os próprios atos, assim como os alheios.

A fenomenologia se ocupa do fenômeno como se mostra e é interpretado a partir de um horizonte. Dessa forma, uma fenomenologia que compreende a sua própria essência deve retornar às condições prévias, deve perguntar, de modo transcendental, pelas condições de sua própria possibilidade (3).

A partir do questionamento do ser e daquilo que este ser faz é possivel empreender a busca para conhecer a enfermagem. Existem especulações e algumas concordâncias quanto ao que a Enfermagem faz, mas muitos profissionais parecem, de certa forma, perdidos e sem uma argumentação satisfatória para fundamentar a razão de seus atos, ou melhor, para posicionar-se de forma congruente com o que pensa, faz, sente e diz. A enfermagem necessita descobrir ou definir sua essência fundamental que, segundo um autor, está orientada para a teoria e a práxis do cuidar (2).

Pensando o cuidar como o que caracteriza a predominância das ações da enfermagem, ela não pode ser considerada tão somente como ciência, já que tudo o que se refere ao cuidado, ao ser humano, enfim, ao cuidado do, para e com o ser humano, jamais poderia ser considerado ou tratado no plano da ciência experimental e positiva. Daí pode-se entender muitos questionamentos, dúvidas e ceticismo acerca do cuidado como vem sendo tratado, ou seja, propondo uma releitura ou talvez, melhor dizendo, buscando seu real significado. Nessa releitura, o cuidado assume um caráter relacional, envolvendo atitudes, comportamentos e ações; é uma forma de ser e estar, portanto é também, de caráter existencial e contextual (4).

O presente trabalho resulta de uma síntese de algumas ideias $(5,6)$, no sentido de explorar, compreender e conhecer melhor o cuidar e o que representa na enfermagem, orientando-se, como referido anteriormente, por uma perspectiva filosófica. Tem, portanto, como objetivo refletir sobre a interpretação de cunho filosófico no que tange ao cuidado na enfermagem e sobre algumas das proposições da autora sobre o tema. Busca contribuir para o conhecimento do cuidado, apresentando fundamentos teóricos que o embasem para sua inclusão na enfermagem. 


\section{Fundamentos teóricos sobre o cuidado}

Não são muitas as tentativas de interpretação acerca do construto cuidado. O cuidar/cuidado como tradicionalmente mais conhecido na área da saúde, vinha sendo utilizado sem uma preocupação maior em explicá-lo ou fundamentá-lo, tampouco saber o que realmente significava. O verbo cuidar é um verbo polissêmico e tem sua origem no latim, estando diretamente relacionado ao verbo curar. Estes termos têm duplo sentido, ou seja, significando não apenas um esforço preocupante, como também significando solicitude (7). De toda a maneira, ambos conotam o sentido de responder a uma necessidade, e podem ser considerados de forma mutuamente implicados.

Interessante destacar que, embora a ação de curar requeira o ato de cuidar, este não implica primeiramente uma condição, uma vez que pode haver cuidado sem cura, porém é difícil obter cura sem cuidado.

Algumas interpretações se notabilizaram ao buscar explorar, compreender e analisar o cuidado na área da enfermagem, tais como: as de ordem religiosa, a qual determinou profundas influências em como o cuidado foi concebido, tanto de forma positiva, como de forma negativa; a interpretação antropológica, cuja autora (8) de renome na enfermagem foi responsável por grande parte de estudos e pesquisas; desenvolveu uma teoria e um método próprio de investigação e através destes estudos, as dimensões culturais do cuidado humano e do cuidado profissional foram desveladas em diversos contextos. Uma interpretação de cunho fenomenológico (9) tem obtido muita receptividade por parte de enfermeiras (os). Sua teoria enfatiza bastante o componente espiritual no encontro cuidador-ser cuidado. Também obteve destaque, tanto do ponto de vista antropológico quanto sociológico, uma análise que enfatizou a questão de gênero e as questões político -econômicas derivadas das práticas de cuidado (10). Este assunto pode ser encontrado em uma publicação que ressalta as diferentes interpretações (6).

Várias estudiosas têm contribuído na enfermagem para ampliar o conhecimento sobre o cuidado e, conseqüentemente, para o progresso do conhecimento da disciplina como um todo. No Brasil, algumas autoras têm se ocupado da temática do cuidado, mas optou-se por não nomeá-las neste trabalho, a fim de evitar alguma exclusão e constrangimentos. Autores que também contribuíram para esclarecer e divulgar o cuidado, em suas múltiplas dimensões, principalmente tendo como origem os fundamentos filosóficos e teleológicos, na sua maioria filósofos, além de Martin Heidegger foram: Leonardo Boff, Milton Mayeroff, Nel Noddings, Sister Simone Roach, Francesc Torralba, Luís E. Hinrichsen, Olinto Pegoraro, entre outros. Todos estes autores derivaram suas interpretações a partir de filósofos da antiguidade, tais como Homero, Platão e Sócrates (11). Entretanto, é na enfermagem que os estudos se avolumaram e ganharam destaque, buscando as raízes do cuidar, principalmente as filosóficas.

\section{Uma interpretação filosófica do cuidado}

Uma das interpretações oriundas da filosofia mais importantes e atuais tem como autor Martim Heidegger sendo um dos mentores do cuidado 
como essência do humano e suas ideias são incorporadas por vários outros filósofos da atualidade, alguns já mencionados anteriormente.

O ser humano, além de atuar no mundo, sente a necessidade de explicar o porquê de suas ações, a razão de seus atos e pensar as razões de cuidar, assim como justificar tal atividade. Para entender a interpretação filosófica do cuidar é necessário falar do Ser que habita o cuidar.

Ser está naquilo que é e como é, na realidade, no ser simplesmente dado. A questão do ente é analisada ao dizer que elaborar a questão do ser significa revelar a transparência de um ente em seu ser. Como modo de ser de um ente, a questão reside justamente no seu próprio questionamento, ou seja, pelo ser o ente que cada um de nós somos e que, entre outras, possui em seu ser a possibilidade de questionar é designada por presença (7). A presença é, pois, o ente do ser, e o sentido existencial da presença é a cura ou cuidado. Ser é a maneira como algo se torna presente, manifesto, percebido, compreendido e finalmente conhecido e que é designado de ser-aî ou ser-no-mundo (7).

Tudo que é percebido, entendido, conhecido de imediato, é ôntico ou existenciário. Portanto, a constituição ontológica do ser-aí é que sua essência está fundada em sua existência e, para que se possa depreender o sentido do ser, deve-se interpretá-lo existencialmente. Por exemplo, buscar compreender o ser doente é procurar decifrar o modo de ser por ele revelado em seu discurso, visualizando o fenômeno que se revela, e como esse fenômeno se revela a partir de si mesmo, pois o pensar fenomenológico é, em última instância, fazer uma reflexão sobre o modo de ser-aí-no-mundo. O ser- aí é um ente situado no mundo, na verdade significa relacionar-se com o mundo, habitar o mundo, mediando-o, interrogando-o. O ser-aí vem de dasein - o modo de existir do homem, único entre os existentes, ele é essencialmente estar no mundo. Dasein está sempre criando, cuidando, preocupado e em desassossego com o mundo, num estado de busca constante e jamais alcança a totalidade. A existência autêntica é sempre uma inquietude de ser, uma luta com o não-ser (7).

O ser realiza-se como ser de linguagem que é um modo de ser, um modo de o ser-aí ir além de si mesmo, constituindo a essência da existência humana. Em outras palavras, o ser e o mundo completam-se e fundem-se. Portanto, ocorre uma construção do ser com o mundo.

Ser-no-mundo é essencialmente zelar, cuidar, existir ao lado das coisas e dos seres, ter interesse, ser-com-os-outros que encontramos no mundo corresponde ao que é denominado de "solicitude". A relação do ser com os outros se caracteriza pela maneira como age, sente e pensa no convivio com seus semelhantes.

\section{Ser com os outros}

Seguindo as digressões de Marting Heidegger, o ser-aí se amplia para o "sendo-com-os-outros" constituindo a característica fundamental no existir do ser humano que só pode definir-se a partir do seu existir, de sua possibilidade de ser ou não ser o que ele é. O cuidar, o relacionar-se com outro é a estrutura fundamental do ser-aí. Cuidar se expressa pela relação 
com o outro dentro do mundo. Existencialmente falando, significa "zelar"; é o desvelar do outro, orientado pela consideração e paciência.

Ao discutir sobre o significado de cuidar e ser cuidado, uma autora (12) aponta para o fato de que as duas partes envolvidas na relação contribuem para ele, existe responsabilidade, compromisso - o cuidado deve ser completado no outro, de alguma forma, se a relação for descrita como uma relação de cuidado. A relação é o reconhecimento do encontro humano que implica uma resposta afetiva. A cuidadora se envolve, sente com o outro e deixa-o ser por si mesmo, há um comprometimento, uma atitude de receptividade para o outro, de preocupação, isto é, o cuidador está presente. A resposta do objeto de cuidado, contudo, não é racional, não é pensada, portanto, embora reconheça a atitude da cuidadora, ele não necessariamente agirá em reconhecimento, fazendo como é esperado.

Como pode se depreender o cuidar, o relacionar-se de forma envolvente e significante com o outro ser corresponde à solicitude, e esta representa a "preocupação com" que é o cuidado $(7,12)$.

O estar com pode dar-se de duas maneiras: como uma forma de se disponibilizar para o outro oferecendo meios para que possa voltar-se a si mesmo, de se conscientizar de suas possibilidades e de assumir seu próprio caminho, seu cuidado (que é quando a cuidadora percebe a possibilidade de o outro vir a crescer); outra forma é a da cuidadora, também, de uma forma envolvente, se adiantar e assumir o encargo que é do outro de cuidar de si mesmo. Dessa forma, o outro fica impedido de ser ele próprio e, mesmo inconsciente e sutil, ocorre uma manipulação e não se concretiza pelo verdadeiro cuidar. Já a primeira forma representa o verdadeiro cuidar, pois permite ao outro vir a ser e cuidar-se e realizar-se. O ser-aíno-mundo-com-os-outros é representado, de forma gráfica, significando o cuidado humano; o cuidado humano é uma forma de viver, de ser, de se relacionar; é uma postura ética frente ao mundo, pois envolve atitudes e valores morais (4).

\section{A interpretação filosófica do cuidado na área da enfermagem}

A enfermagem adotou algumas idéias de autores da área da filosofia e estas ideias podem servir de sustentáculo para uma fundamentação do cuidar, explicando alguns vazios e inconsistências em relação a temática. Parece que as tradicionais idéias sobre o cuidar como uma série de tarefas previsíveis e de cunho técnico, dependentes das orientações médicas não são mais suficientes. Um movimento a favor de mudanças e de rejeição ao modelo biomédico sustentado pelo paradigma cartesiano, vendo o sujeito como um todo, pleiteando relações mais próximas, são fatores decisivos para incorporar vários estudos os quais oferecem uma releitura na forma de fazer e pensar o cuidar.

Os valores, crenças e práticas tendem a estarem embutidas nas visões de mundo, na linguagem, na religião nas relações sociais, na política, na educação, na economia, na história e no contexto ambiental de cada cultura humana. 
O cuidar constitui uma prática que além de suas características técnicas, envolve sentimento, ou melhor, é uma prática que envolve conhecimento e o aspecto moral $(1,4)$. Um cuidado autêntico representa quando profissionais da enfermagem respondem às necessidades de cuidado e agem responsavelmente ajudando a desenvolver, restaurar ou aumentar o cuidado de si na melhor maneira possível. Ao agir assim, os pacientes não são apenas ajudados a lidar e enfrentar a doença e a incapacidade, mas são encorajados e empoderados a continuar em sua busca pela plenitude humana. A enfermagem ao se caracterizar como uma prática de cuidar tem a ética incorporada em sua prática (4).

Uma teorista de renome (9) internacional coloca que a enfermagem consiste na ciência e filosofia do cuidado. Os fatores de cuidado, representando o ponto central da enfermagem, foram recentemente expandidos passando a se denominar de processo clínico caritativo que pode ser traduzido como um processo clínico baseado na compaixão, na benevolência ou amor-caridade. Desta forma a autora parece apoiar e integrar tanto aspectos técnico-científicos como humanísticos em sua teoria. Estas perspectivas que representam ideias e valores os quais evoluíram através dos anos resultaram em uma maneira mais ampla de o cuidado ser considerado. De tal maneira que a autora afirma que considera hoje seu trabalho como uma visão mais filosófica, ética, intelectual para a disciplina de enfermagem desenvolvendo uma fonte disciplinar/profissional ao invés de uma específica teoria per si. O momento de cuidar dependendo de certas orientações filosóficas pode transcender tempo e espaço. Ela vai mais longe, afirmando que uma relação de cuidado transpessoal se desloca além do ego-self irradiando-se para a dimensão espiritual, inclusive abrangendo preocupações cósmicas e possibilitando a auto-cura e o desenvolvimento dos potenciais de cada um. Desta forma, pode ser visto que sua teoria se torna bastante complexa, principalmente considerando os paradigmas conservadoristas que caracterizam a maioria dos sistemas de saúde no mundo (9).

Uma importante contribuição no que se refere aos estudos sobre o cuidado e dada por uma teóloga e filósofa de enfermagem, Sister Simone Roach. Em seu trabalho discursa sobre a ontologia do cuidar e afirma que cuidar é a maneira humana de ser: ele é a expressão de nossa humanidade e com estas afirmativas fica clara sua afinidade com o pensamento heideggeriano. A significância do cuidar envolve responsabilidade, o cuidado responde por um valor humano. A resposta para a crise de valores que as sociedades enfrentam, nos dias de hoje, está em acreditar que como seres humanos nossa missão primordial no mundo é cuidar (4).

Ao se utilizar uma abordagem fenomenológica para o cuidado alguns pontos podem ser considerados para uma reformulação de conceitos. Alguns deles podem ser destacados, tais como "re-descobrir o ser no ato de cuidar"; "utilizar uma metodologia da compreensão"; "disposição para ouvir"; "buscar o sentido dos sinais e sintomas no ato de tocar", além de outros (13). 


\section{Uma visão do cuidado na enfermagem tomando como base a fenomenologia e o holismo}

Duas concepções filosóficas são tomadas como base para a interpretação da autora do presente texto: a fenomenologia e o holismo. O holismo parte de uma visão de totalidade; é fruto de uma nova proposta paradigmática cuja visão enaltece o ser e seu desenvolvimento interior. Ser é mais importante do que ter. Nesta visão, o todo é mais do que a soma das partes; a partir do conjunto tem-se o significado das partes.

Como já colocado no inicio do trabalho, o cuidado, de forma geral, é considerado como uma forma de ser e estar no mundo e representa o cuidar humano; existe uma relação entre o eu/self, o outro e o cosmos, ou seja, o ser-aî-no-mundo se define pelas formas ou maneiras de experienciar cuidado e pelas relações (de cuidado) que estabelece consigo mesmo, com os outros e com o meio que o cerca distinguindo-o como ser humano e lhe conferindo o status humano (4). Nosso estar no mundo inclui o cuidar de si, dos outros seres e do meio em que habitamos cujas influencias são inegáveis no que tange aos aspectos sociais, mentais físicos, espirituais e na forma como o ser vivencia a saúde e a doença. O ser humano faz parte de um todo, e ao cuidar, somos não só parte do todo, somos o todo, e nosso compromisso se estende a nossa morada, a Terra, preservando todos os seres vivos que contribuem para um viver com base na sustentabilidade.

O cuidar no entender da autora deste artigo se define como uma forma de viver, de ser e de se expressar; é uma postura ética e estética que o ser assume frente ao mundo. Compreende ainda um compromisso com o estar-no-mundo contribuindo com o bem-estar geral, com a preservação da natureza, com a promoção das potencialidades, suas e dos outros e na dignidade e espiritualidade humanas. O ser, desta forma entendida como um ser de cuidado contribui na construção da história, do conhecimento e da vida (4).

O ser humano, ao longo de sua trajetória desenvolveu hábitos e comportamentos de cuidar, que se iniciaram basicamente de duas formas: como um modo de sobrevivência e como uma expressão de interesse direcionado a coisas ou outros seres. O cuidar se caracteriza como um potencial que os seres possuem e que pode ser desencadeado de acordo com as circunstâncias e o contexto, portanto será mais ou menos desenvolvido e sofrerá influências na forma como as pessoas foram cuidadas durante as etapas da vida. Cultura, política, economia, religião, entre outros fatores, também intervém nas maneiras de cuidar. O que se pode observar é que essas maneiras de cuidar apresentam paradoxos e ambiguidades traduzindo-se em comportamentos de cuidado, como também de não cuidado.

Mais recentemente, outros paradigmas têm se insinuado e na área da saúde algumas mudanças já são evidenciadas, como a tendência a um enfoque mais humanista. O pluralismo, a diversidade, a interdisciplinaridade são algumas das tônicas para o novo milênio e, entre elas, também o resgate do cuidado humano. O resgate do cuidado na enfermagem, ao contrário do que algumas pessoas temem, não significa uma rejeição aos 
aspectos técnicos, tampouco ao seu aspecto científico. O que se pretende ao relevar o cuidar é enfatizar a característica de processo interativo, destacando o ser humano nesse processo e sua circunstância, assim como relevar o componente emocional, e da intuição que caracterizam a dimensão artística do cuidado, além da dimensão moral que contém.

O cuidado compõe a linguagem da enfermagem e ao visualizá-lo como um modo de ser, relacional e contextual, caracteriza-se por ser a única ação verdadeiramente independente da enfermagem. O cuidado não pode ser prescrito; terapêuticas, técnicas, intervenções, procedimentos podem ser prescritos, não o cuidado. Não se prescreve um modo de ser, não se ditam ou criam regras ou normas de cuidar, ou maneiras de se comportar. Eles podem ser sugeridos, recomendados, aconselhados, não prescritos (4). Não quer dizer que, ao longo dos anos a enfermagem não tenha se sujeitado a normas e se caracterizado por ensinar em seus currículos de enfermagem de cunho behaviorista, certos comportamentos normatizados.

O cuidar, na enfermagem compreende os comportamentos e atitudes demonstradas nas ações pertinentes a cada categoria asseguradas por lei. Estas ações, desenvolvidas com competência tem o objetivo de favorecer as potencialidades das pessoas no sentido de manter ou melhorar a condição humana no processo de viver e morrer (4). Por competência a autora entende todas as qualidades necessárias ao desempenho das atividades de enfermagem as quais podem ser expressas através de conhecimento, habilidades e destreza manual, criatividade, sensibilidade, pensamento crítico, julgamento e na capacidade de tomar decisões. Os comportamentos e atitudes, por sua vez, compreendem uma vasta lista, onde se destacam: respeito, gentileza, compaixão, responsabilidade, disponibilidade, oferecimento de segurança, apoio, conforto, consideração e carinho (4).

O processo de cuidar é a forma como se dá o cuidado. É um processo interativo que ocorre entre cuidadora e ser cuidado em que a primeira tem um papel ativo, pois desenvolve ações acompanhadas de comportamentos de cuidar. Já o segundo, o ser cuidado, tem um papel mais passivo e, em função de sua situação, pode tornar-se dependente, temporariamente, mudando para um papel menos passivo, contribuindo no cuidado, e ser responsável pelo próprio cuidado (5).

O processo de cuidar "constitui todas as atividades desenvolvidas pela cuidadora para e com o ser cuidado com base em conhecimento científico, habilidade, intuição, pensamento crítico, criatividade, acompanhadas de comportamentos e atitudes de cuidar no sentido de promover, manter e/ ou recuperar sua dignidade e totalidade humanas. Essa dignidade e totalidade englobam o sentido de integridade buscando a plenitude física e/ou, mental, moral, emocional, social e espiritual nas fases do viver e do morrer, constituindo-se, em última análise, em um processo de transformação de ambos, cuidadora e ser cuidado" (4). O processo de cuidar, assim como definido é visualizado em uma forma gráfica e todos os seus componentes são descritos pormenorizadamente e foram atualizados no decorrer dos anos $(4,6)$. A cuidadora ao cuidar, no seu verdadeiro sentido relaciona-se 
com o outro ser exprimindo seu ser, seu conhecimento e sensibilidade, demonstrando habilidade técnica e espiritualidade, elevando e ajudando-o a crescer. O outro, em sua experiência genuína, compartilha seu ser, seu conhecimento, seus rituais de cuidado, suas características, que auxiliarão no processo de cuidar. Assim o paciente/ ser cuidado, contribui no processo de atualização da cuidadora, no seu aprimoramento, ou seja, no seu vir a ser mais, como profissional e como pessoa (6).

Em suma, cuidar é presença, solicitude e preocupação; é um ato de responsabilidade que o profissional exibe, quando incorpora os princípios e valores do cuidado. Há um envolvimento genuíno ao entender, respeitar e ajudar o ser que se encontra vulnerável.

O processo de cuidar pressupõe uma dimensão ética e estética porque envolve uma ação humana a qual inclui beleza e bondade. Esta idéia foi tomada por empréstimo de um autor (2), pois explica, de forma clara, como o cuidar se caracteriza como arte e porque é considerado ético: é arte porque integra técnica, intuição e sensibilidade. É ético porque integra uma ação responsável e tem como objetivo o bem-estar do outro, seu desenvolvimento e sua plenitude de forma integral. Na visão da autora deste texto, a ação de cuidar, como se viu engloba sentimentos e comportamentos, além de ações e o seu objetivo, na enfermagem, é aliviar o sofrimento humano, manter a dignidade e facilitar meios para manejar com as crises e com as experiências do viver e do morrer. O trabalho completo acerca das ideias da autora pode ser consultado em algumas publicações, algumas delas referenciadas no presente texto (4-6).

\section{Considerações finais}

Cuidado é um conceito polissêmico e, portanto, adquire múltiplos significados. Na perspectiva filosófica o cuidar é um modo de ser no mundo e é o que confere a condição de humanidade ao ser. Dessa forma, pode-se dizer que todo o ser humano é um ser de cuidado, nasce com o potencial de cuidar. Contudo, nem todas as pessoas cuidam em seu sentido ético e estético, ou seja, demonstrando sensibilidade e responsabilidade. Práticas e comportamentos de não cuidado abundam no mundo de hoje.

$\mathrm{Na}$ enfermagem não é diferente: nem todos os profissionais de enfermagem cuidam no seu real sentido. Ações terapêuticas, intervenções, procedimentos, técnicas, constituem uma vasta lista de "tarefas" denominadas tradicionalmente cuidados de enfermagem. O que distingue o cuidar não é o que se faz, mas como se faz, ou seja, como se cuida e como já mencionado, é acompanhado de comportamentos e atitudes, caracterizadas como de cuidado. Realizar um procedimento em um corpo qualquer não constitui cuidado, é como o termo exprime, ou seja, um procedimento. Cuidado só passa a ser verdadeiramente uma ação moral, enobrecedora quando realizada em um ser humano e, preferentemente para e com o ser, sujeito do cuidado. É uma ação interativa que ocorre entre ser que cuida e ser que é cuidado e engloba envolvimento, comprometimento. A autora do presente manuscrito visualiza o cuidar como um fenômeno existencial, 
relacional e contextual. Existencial porque faz parte do ser e repetindo, é o que diferencia o ser como um ser "humano", dotado de racionalidade, cognição, intuição e espiritualidade, portanto, de sensibilidade e de sentimentos. Relacional porque ocorre, e só ocorre, em relação ao outro, na coexistência com outros seres, na convivialidade. E contextual porque assume variações, intensidades e diferenças nas suas maneiras e expressões de cuidar conforme o meio, o contexto em que se apresenta a cada momento. O cuidado deve ser sentido, vivido; e para que o cuidado seja integrado no nosso dia-a-dia é preciso absorvê-lo, permitir que ele faça parte de cada um de nós, transformando-o em estilo de vida.

Finalmente, espera-se com este manuscrito aclarar o fenômeno cuidado, em sua interpretação filosófica e mais humanista. Lembrando que o cuidar, como considerado por vários autores na enfermagem, constitui sua essência, portanto, é vital que não se esgotem as tentativas de explorar este fenômeno, aplicando seus princípios à pratica de forma a contribuir para o conhecimento da enfermagem e para que sujeitos a receber cuidado se beneficiem e valorizem os profissionais que o expressam e o praticam.

Este texto, além de objetivar contribuir na exploração do tema cuidado e apresentar algumas ideias sobre o mesmo em sua visão filosófica, busca sensibilizar para que estas ideias possam servir de reflexão no sentido de motivar debates sobre o assunto no meio da enfermagem.

\section{Referências}

1. Jaspers K. Iniciação filosófica. Lisboa: Guimarães; 1998.

2. Torralba F. Antropologia do cuidar. Petrópolis: Vozes; 2009.

3. Rabuske EA. Antropologia filosófica. Petrópolis: Vozes; 2003.

4. Waldow VR. Cuidar: expressão humanizadora da enfermagem. $6^{\mathrm{a}}$ ed. Petrópolis: Vozes; 2012.

5. Waldow VR. O cuidado na saúde: as relações entre o eu, o outro e o cosmos. Petrópolis: Vozes; 2004.

6. Waldow VR. Bases e princípios do conhecimento e da arte da enfermagem. Petrópolis: Vozes; 2008.

7. Heidegger M. Ser e tempo. 10ª ed. Petrópolis: Vozes; 2001.

8. Leininger MM, McFarland MR. Culture care diversity and universality: a worldwide nursing theory. Boston: Jones \& Bartlett; 2006.

9. Watson J, Browning R. Viewpoint: caring science meets heart science: a guide to authentic caring practice. Am Nurse Today [internet]. 2012 [citado 2013 maio 5];7(8). Disponível em: http://www.americannursetoday.com/AuthorGuidelines.aspx.

10. Collière MF. Promover a vida: da prática das mulheres de virtude aos cuidados de enfermagem. $2^{a}$ ed. Lisboa: Sindicato dos Enfermeiros Portugueses; 1989.

11. Costa ML. Educar para cuidar [videocassete]. Maceió: 63 CBEnEditora TVMED Comércio Ltda; 2011.

12. Noddings N. O cuidado: uma abordagem feminina à ética e à educação moral. São Leopoldo: Editora Unisinos; 2003. 
13. Graças EM, Santos GF. Metodologia do cuidar em enfermagem na abordagem fenomenológica. Rev Esc Enferm USP [internet]. 2009 [citado 2013 maio 29];43(1):200-7. Disponivel em: http://www.scielo.br/ scielo.php?script=sci_arttext@pid=S0080-62342009000100026@ Ing $=\mathrm{pt}$. 